\title{
The effect of d-amphetamine on chained fixed-interval schedule behavior ${ }^{1}$
}

WARREN M. STEINMAN UNIVERSITY OF ILLINOIS

To test the hypothesis that d-amphetamine increases low rate behavior and decreases high-rate behavior, two pigeons were trained on a three-component fixed-interval chain. The effects of six dosages were then examined. It was found that at intermediate dosages response rates in the middle component of the chain were increased, whereas they were reduced in the final component. The major effect of the drug upon the initial component was to eliminate long pausing.

In a recent article, Gibson (1967) examined the behavior of pigeons or a multiple FR DRL schedule of reinforcement. He found that whereas the d-amphetamine increased rates during the DRL condition, it decreased the response rates during the FR condition. Combining these results with others available in the literature, Gibson concluded that an effect of damphetamine is to increase response rates if they are low and decrease the rates if they are high.

In the present experiment, Gibson's hypothesis is investigated by noting the effect of various dosages of d-amphetamine upon behavior in a three-component chained fixed-interval schedule (chain FI/FI/FI). The use of a chained schedule for this purpose has many advantages. Unlike a multiple FR DRL schedule, a chain FI/FI/FI does not require the animal to learn different response strategies. The response criterion in each component of the chain is identical. Furthermore, in a chained schedule, unlike an FR or a DRL schedule changes in general activity which may be produced by the drug have very little effect upon the attainment of reinforcement. Thus, changes that may occur in the chained-schedule behavior may be more accurately attributed to the drug's effects rather than some interaction between the drug's effect and the frequency of reinforcement. Finally, since chained schedules generally produce very different response rates in each component (Kelleher \& Fry, 1962), they should be ideally suited for a test of Gibson's conclusion.

\section{Subjects}

Two adult Carneaux pigeons served as Ss. They were maintained throughout the experiment at $70 \%$ of their free-feeding body weights.

\section{Apparatus}

The experimental chamber was a standard two-key pigeon box (Ferster \& Skinner, 1957). All programming equipment was automatic and silent.

\section{Procedure}

After magazine training, Ss were trained to peck a red key which on a FI-4 sec schedule resulted in $3 \mathrm{sec}$ access to grain. The schedule requirement was then increased to $8 \mathrm{sec}$. Next, a yellow key was presented, which on a FI-4 sec schedule produced a blue color on the key. Pecking the blue key on an FI-4 sec schedule produced a red key, and pecking the red key on an FI-4 sec schedule resulted in the delivery of grain. The interval requirement was then increased to $8 \mathrm{sec}$ in each of the three components, then to $16 \mathrm{sec}$, then to $32 \mathrm{sec}$, and finally to $64 \mathrm{sec}$ where it remained for the remainder of the experiment. For the first 25 sessions the length of each session varied between 32 and 128 completed chains. Following the 25th session, each session lasted a maximum of $4 \mathrm{~h}$, or a minimum of 32 completed chains. The first drug injection was attempted only after $\mathrm{S}$ demonstrated typical chain FI/FI/FI behavior for at least five consecutive sessions. Between each drug test at least two sessions of normal chained-scheduled behavior had to be in evidence, and the drug was not injected until eight chains at the beginning of the session had been completed. Sixdosages of d-amphetamine were presented intramuscularly in the following order: 0.5 , $6,2,4,10$, and $1 \mathrm{mg} / \mathrm{kg}$. Three replications at each dosage were obtained.

\section{Results and Discussion}

The baseline performance of both Ss was consistent with the description of chain FI/FI/FI behavior given by Kelleher \& Fry (1962). Response rates in the third component of the chain $\left(\mathrm{Y}_{3}\right)$, the component most distant from reinforcement, were extremely low, averaging between 1 and 2 responses. In addition, $Y_{3}$ frequently contained pauses of between 5 and $45 \mathrm{~min}$ before the one response necessary to terminate the component was emitted. In the second component $\left(\mathrm{B}_{2}\right)$, the baseline responding was positively accelerated and averaged 30 responses for $S_{1}$ and 36 responses for $S_{2}$. The length of $\mathrm{B}_{2}$ was seldom much longer than the $64 \mathrm{sec}$ minimum. Responding in the first component $\left(R_{1}\right)$ was again positively accelerated with an average of 53 responses for $S_{1}$ and an average of 81 responses for $S_{2}$. Pausing was very rarely seen in $R_{1}$.

The average number of responses emitted at each dosage is presented in Fig. 1. Except for the $10 \mathrm{mg} / \mathrm{kg}$ dosage, each point in Fig. 1 is a mean of 72 chains, i.e., the 24 chains Immediately following an injection multiplied by the three replications at each dosage. At the lowest dosage $(0.5 \mathrm{mg} / \mathrm{kg})$ the major effect of the drug was to eliminate the long pausing which previously was typical of the behavior during $\mathrm{Y}_{3}$. However, the number of responses emitted at this dosage was not greatly effected. At the highest dosage $(10 \mathrm{mg} / \mathrm{kg})$ all behavior ceased for periods as long as 5 to $8 \mathrm{~h}$ after a few chains were completed. At intermediate dosages 


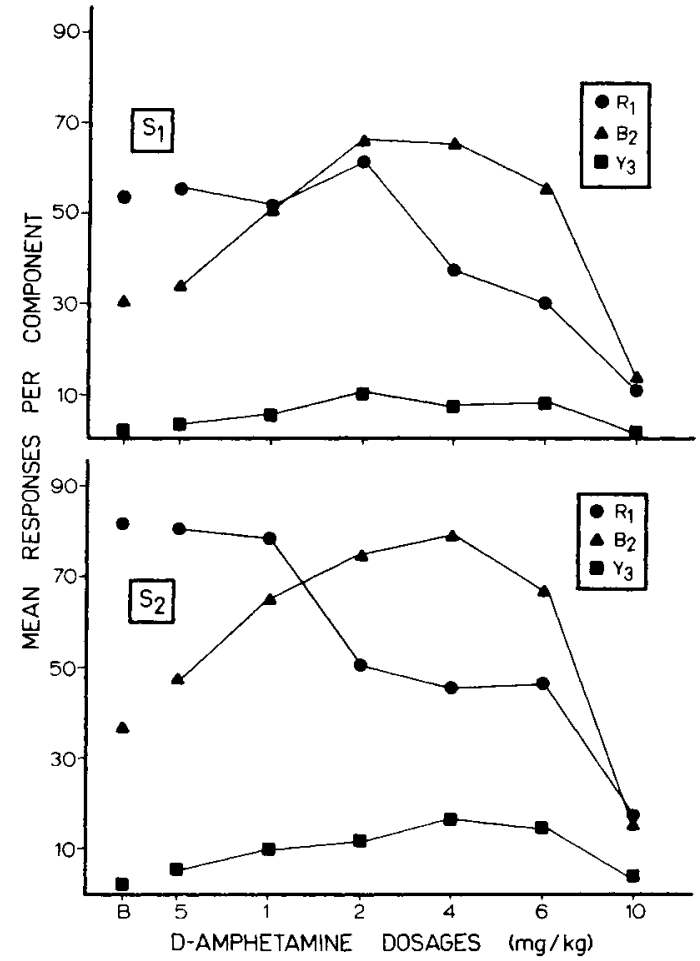

Fig. 1. Mean responses emitted in each component of the chain FI/FI/FI as a function of the d-amphetamine dosage. "B" refers to the mean baseline rate. Each point is a mean of 72 observations, i.e., the 24 chains immediately following an injection on each of three replications.

the three components were differentially affected. Although the absolute number of responses emitted in the third component of the chain $\left(\mathrm{Y}_{3}\right)$ increased systematically as a function of dosage up to the highest dosage, the increase in responding was slight. A more striking result of the drug within $Y_{3}$ was its tendency to completely eliminate third-component pauses. In contrast, the behavior during the second component $\left(\mathrm{B}_{2}\right)$ was markedly increased at the intermediate dosages. Rates of two to three times those of baseline were noted. In the last component of the chain $\left(R_{1}\right)$, the drug systematically reduced the number of responses as a function of the dosage.

Although these results do lend support to Gibson's analysis of the behavioral effects of d-amphetamine, it is clear that the drug's effects are more complicated than Gibson's statement would lead one to believe. Indeed, low rate responding was increased by the drug and the high rate responding was decreased. However, why, at the same dosage, responding during $B_{2}$ should increase to a level above that emitted in $R_{1}$ is unclear. As pure speculation, it is suggested that a basis for this result might involve an interaction between the appetitedepressant characteristics of d-amphetamine and its behavioral activation effect.

Often Ss were observed to disregard the food magazine and also to disregard scattered grain on the floor of the chamber when they were under the influence of the 6 and $10 \mathrm{mg} / \mathrm{kg}$ dosages of the drug. Similiarly, they often did not eat for several hours when returned to their home cages. If as a result of the drug the food was less reinforcing, the decreased behavior during $R_{1}$ is understandable, since responding during $R_{1}$ is directly maintained by the delivery of food. On the other hand, behavior during the second component of the chain $\left(B_{2}\right)$ is only indirectly maintained by the food. The immediate consequence of performing during $\mathrm{B}_{2}$ is the delivery of the red key light. Perhaps, the conditioned reinforcing properties of $R_{1}$ had become partially independent of the current discriminative properties of that stimulus. If so, $R_{1}$ might have remained effective as a conditioned reinforcer allowing the activating effect of d-amphetamine to be apparent in $\mathrm{B}_{2}$, while at the same time the discriminative properties of $R_{1}$ resulted in a lowered response rate because of the relatively aversive nature of the food for a drugged animal. One would expect if this analysis were true, that continued presentations of the d-amphetamine would eventually eliminate the rate increases found in $\mathrm{B}_{2}$. However, no such trend was apparent within the three replications investigated.

\section{References}

FERSTER, C. B., \& SKINNER, B. F. Schedules of Reinforcement. New York: Appleton-Century-Crofts, 1957.

GIBSON, D. A. Effects of d-amphetamine on multiple schedule performance in the pigeon. Psychon. Sci, 1967, 7, 3-4.

KELLEHER, R. T., \& FRY, W. T. Stimulus functions in chained fixed-interval schedules. J. exp. Anal Behav., 1962, 5, 167-173.

Notes

1. This research was supported in part by Grant No. 13111-01 from the National Institutes of Mental Health. 